\title{
Characterization of Epitaxial Bands and Electron Beam Damage in Natural Zircon Using Cathodoluminescence.
}

\author{
Jacob L. Mey* and Angela Klaus* \\ *American Museum of Natural History, New York, NY 10024, USA.
}

Natural zircons $\left(\mathrm{Zr}\left[\mathrm{SiO}_{4}\right]\right)$ usually show bright cathodoluminescence $(\mathrm{CL})$, often displaying a complex pattern of parallel bands epitaxial to the crystallographic facets of the crystal rim or the core shape (Fig. 1). These bands are not visible in backscattered electron (BSE) images (Fig. 3) or secondary electron (SE) images (Fig. 2), because these bands neither represent detectable atomic number differences in the crystal lattice, nor topographical features on the surface. The cathodoluminescence spectra of zircons, most likely, represent slight fabric strains, related to deformation of the crystal lattice[1]. Such slight differences in fabric can also be caused by trace amounts of elemental misfits in the crystal framework, various growth events or failed annealing during metamorphism throughout the zircon's geological history [2]. Fabric characteristics related to element traces causing crystallographic misfits are not easily quantified with analytical techniques such as energy dispersive x-ray spectroscopy (EDS) mapping or wavelength dispersive $\mathrm{x}$-ray spectroscopy (WDS) analysis [1,2].

Zircons from a kimberlitic type rock from Telemark of central Norway [3] were analyzed (for a different study) using a five spectrometer Cameca SX-100 microprobe, utilizing two different electron beam settings (see Fig. 2). The zircons were subsequently, for the purpose here, imaged on a Hitachi S-4700 cold field emission (FE) scanning electron microscope (SEM) equipped with BSE (GW Electronics - Centaurus), EDS (Princeton Gamma Tech) and high resolution CL (Gatan MonoCL 3) detectors. Highly resolved CL spectra of the zircons were collected at several different bandwidths, each spanning 50-100 $\mathrm{nm}$. The resulting images represent bandwidth dependent levels of zircon CL intensity in the detectable spectrum ranging from 400$880 \mathrm{~nm}$. Spectra from the beam damaged spots (see Fig. 1) were also collected and compared to those collected from the immediate vicinity.

The resulting images were colored, approximately to their true bandwith colors, and used as a method for characterizing differences among the epitaxial bands. Furthermore, the microprobe electron beam showed a marked effect on the CL in several zones in the zircon. Most notably in the central core of the zircon where CL is naturally absent, a clear CL signal was developed as a consequence of the beam-zircon interaction (Fig. 1). This effect is lasting and showed no fading in signal intensity over the course of study.

[1] F. Bertram et al., App. Physics Lett., Vol. 74, No. 3. 18. (1999)

[2] S. Bodorkos et al., American Jounal of Science 300 (1), p. 60-82. (2000)

[3] J. L. Mey, Cand. Scient. Thesis, University of Aarhus, Denmark (1999) 


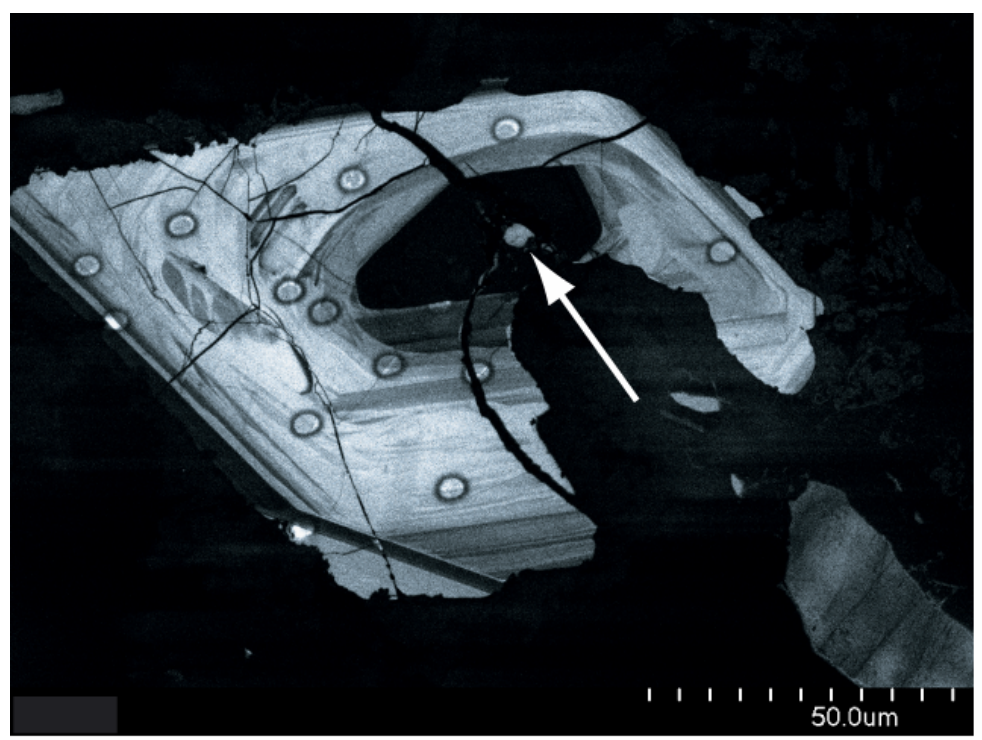

Fig. 1: Image showing cathodoluminescence $(\mathrm{CL})$ in a zircon grain. Spots are damages caused by a $20 \mathrm{kV}$ - $200 \mathrm{nA}$ microprobe beam. Spots from the $15 \mathrm{kV}-10 \mathrm{nA}$ beam are not visible.

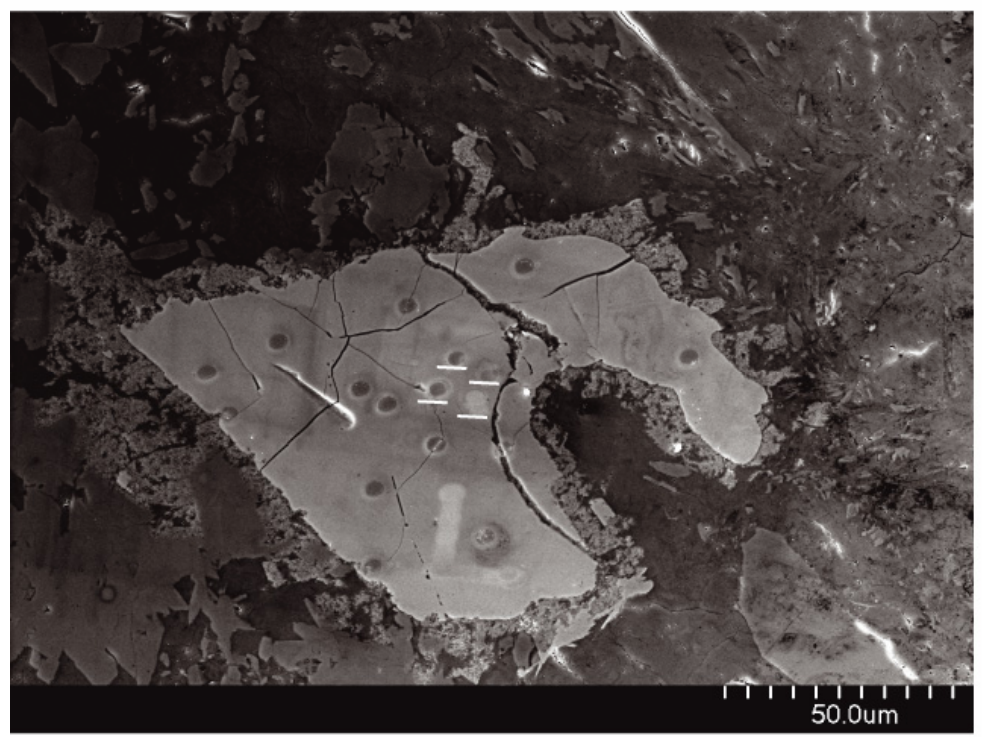

Fig. 2: Image showing secondary electron (SE) emission of a zircon grain. Spots seen here are damages caused by both the $20 \mathrm{kV}-200 \mathrm{nA}$ and a $15 \mathrm{kV}-10 \mathrm{nA}$ beam ( the latter annotated with white lines).

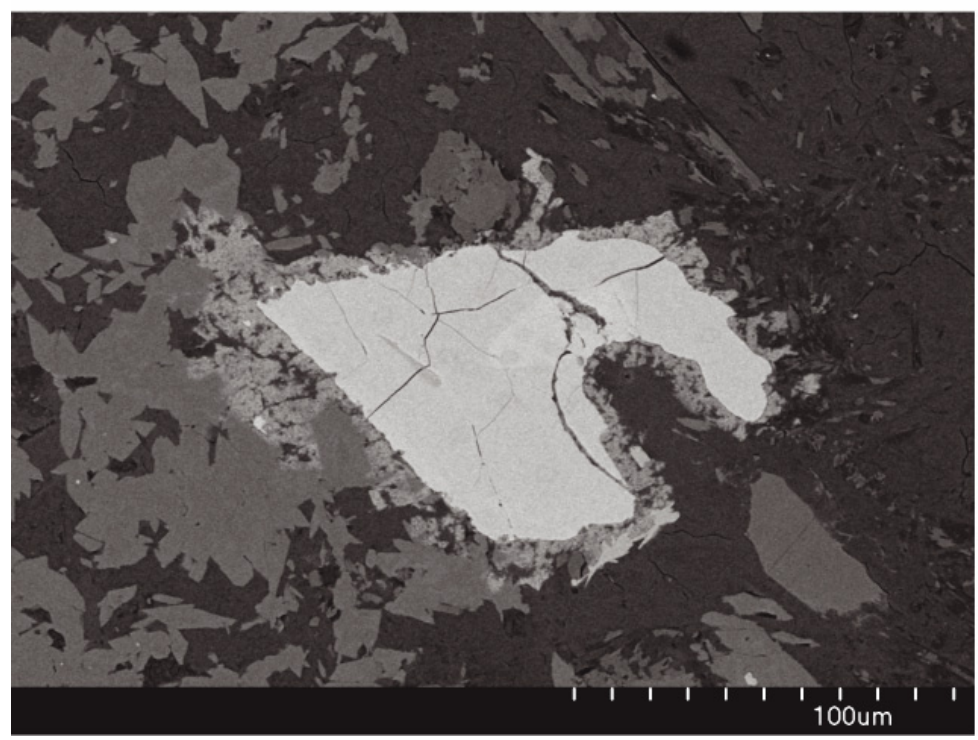

Fig. 3: Image showing backscattered electron (BSE) emission of a zircon grain. Damage spots by either $20 \mathrm{kV}-200 \mathrm{nA}$ or $15 \mathrm{kV}-10 \mathrm{nA}$ beams are barely detectable. 